\title{
Use of genetically engineered stem cells for glioma therapy (Review)
}

\author{
HIROKI NAMBA, HIROSHI KAWAJI and TOMOHIRO YAMASAKI \\ Department of Neurosurgery, Hamamatsu University School of Medicine, Hamamatsu, Shizuoka 431-3192, Japan
}

Received November 13, 2014; Accepted September 24, 2015

DOI: $10.3892 / \mathrm{ol} .2015 .3860$

\begin{abstract}
Glioblastoma, the most common and most malignant type of primary brain tumor, is associated with poor prognosis, even when treated using combined therapies, including surgery followed by concomitant radiotherapy with temozolomide-based chemotherapy. The invasive nature of this type of tumor is a major reason underlying treatment failure. The tumor-tropic ability of neural and mesenchymal stem cells offers an alternative therapeutic approach, where these cells may be used as vehicles for the invasion of tumors. Stem cell-based therapy is particularly attractive due to its tumor selectivity, meaning that the stem cells are able to target tumor cells without harming healthy brain tissue, as well as the extensive tumor tropism of stem cells when delivering anti-tumor substances, even to distant tumor microsatellites. Stem cells have previously been used to deliver cytokine genes, suicide genes and oncolytic viruses. The present review will summarize current trends in experimental studies of stem cell-based gene therapy against gliomas, and discuss the potential concerns for translating these promising strategies into clinical use.
\end{abstract}

\section{Contents}

1. Introduction

2. Tumor tropism of stem cells

3. Types of cell vector

4. Cytokine-based therapy

5. Enzyme/prodrug-based therapy ('suicide' gene therapy)

6. Oncolytic virus-based therapy

7. Conclusion

Correspondence to: Professor Hiroki Namba, Department of Neurosurgery, Hamamatsu University School of Medicine, 1-20-1 Handayama, Hamamatsu, Shizuoka 431-3192, Japan

E-mail: hnamba@hama-med.ac.jp

Key words: gene therapy, glioma, migration, stem cell-based therapy, therapeutic vehicles

\section{Introduction}

Gliomas account for $\sim 30 \%$ of all brain tumors, and are the most common primary tumors of the central nervous system in Japan (1). Glioblastoma multiforme (GBM), the most common and most malignant type of glioma, has a median survival time of 14.6 months and a 5-year survival rate of $<10 \%$, despite various therapeutic strategies, including surgery, radiotherapy and chemotherapy with temozolomide $(2,3)$. Complete surgical removal of GBM is not possible due to the invasive nature of gliomas to the surrounding healthy brain tissue, and the majority of patients die within 1 year of diagnosis as a result of a novel secondary tumor foci forming within $2 \mathrm{~cm}$ of the resected area $(4,5)$. Residual tumor cells are typically resistant to standard radiotherapy, and efficient chemotherapy cannot be delivered due to the presence of the blood-brain barrier (BBB) and systemic toxicity (6). The potential effects of radiotherapy on GBM are limited by the associated toxicity to normal tissues. In addition, the efficiency of chemotherapy is also limited, as chemotherapeutic agents are unable to efficiently cross the BBB, while glioma cells also have a high tendency to develop resistance against chemotherapeutic agents. Therefore, novel therapeutic strategies to eliminate invasive tumor cells without damaging the normal brain parenchyma are urgently required (7-9).

Gliomas rarely metastasize outside of the central nervous system, and the majority of recurrence occurs proximal to the resection site, therefore malignant gliomas are recognized as good candidates for local gene therapy (10). One of the first and most widely used local gene therapies is that of the herpes simplex virus-thymidine kinase (HSV-tk)/ganciclovir (GCV) system. However, while clinical studies regarding the retrovirus-mediated $\mathrm{HSV}$-tk/GCV gene therapy have been conducted, only clinical safety has been proven and no therapeutic benefits have been confirmed (10). Although promising results have been observed in studies of viral-mediated gene therapy in animal models of glioma (11), clinical studies have achieved limited success in the attenuation of tumor growth and extension of patient survival (12). These poor results associated with the use of the viral system are associated with, at least in part, the limited distribution of viral vectors throughout the invasive tumor (12). In order to improve the treatment field of local gene therapy, stem cells-based strategies were subsequently introduced.

Recent advances in neural stem cell (NSC) research suggest that the use of genetically engineered NSCs to 
produce anti-tumor substances has notable advantages over viral vector-mediated gene delivery of therapeutic genes to gliomas, as NSCs exhibit extensive tropism for intracranial lesions, including gliomas (13). Numerous laboratories have replicated this migratory capacity using various types of stem cell, including multipotent mesenchymal stem cells (MSCs) $(14,15)$, in animal models. In contrast to viral vectors, stem cells are primarily attracted to tumor tissue and not to normal neural cells, and therefore tumor-specific gene delivery is achieved, whilst minimal side effects are exerted on the normal brain tissue $(13,16)$.

Over the past decade, significant attention has been paid to stem cell-based strategies as alternative therapies for the treatment of malignant gliomas. This is a result of the fundamental ability of stem cells to migrate to brain tumors, regardless of the BBB (13). Since then, a wide variety of stem cell-based therapeutics have been evaluated (17). Stem cells are relatively easy to modify to carry therapeutic genes (18) and exert immunosuppressive properties that may abrogate host immunoreaction following implantation (19-22). These cells are also capable of protecting oncolytic viruses from the host immune response, thereby establishing long-term supplies of the therapeutic virus at the tumor site (23).

The present review aims to summarize the current status of genetically engineered stem cell-based gene therapy for the treatment of glioma. The types of cell and therapeutic transgene to be used will be discussed in terms of efficacy and safety for translating experimental findings to a clinical setting.

\section{Tumor tropism of stem cells}

NSCs and other types of stem cell exhibit tropism for sites of tissue damage, as well as the tumor microenvironment, where a variety of substances are secreted (19), including inflammatory-derived factors and angiogenic factors. Activated astrocytic and microglial cells in the peritumoral edema zone generate an inflammatory tumor microenvironment in glioma $(24,25)$. Interleukin (IL)-8 (26), monocyte chemotactic protein (MCP)-1 (27) and stromal cell-derived factor (SDF)-1 $\alpha$ (28) in the peritumoral reactive region attract MSCs. Tumor necrosis factor (TNF)- $\alpha$ contributes to enhancement of the expression of the CXC chemokine receptor (CXCR) 4 on MSCs, which facilitates the chemotactic invasiveness of MSCs towards stroma-derived SDF-1 $\alpha$ (29). This effect is also observed in induced pluripotent stem cells (iPSCs) $(30,31)$. MCP-1 expression in gliomas may mediate glioma-tropic migration of NSCs via the CC chemokine receptor 2 (32). Therapeutic irradiation further enhances MSC tropism to glioma, via the inflammatory response $(33,34)$.

Tumor tropism of MSCs is enhanced by tumor angiogenesis and angiogenic signaling molecules including platelet-derived growth factor (PDGF)-BB, PDGF-D $(14,16)$, vascular endothelial growth factor (VEGF)-A, transforming growth factor- $\beta 1$ and neurotrophin-3 $(35,36)$. NSC migration is also influenced by angiogenic signaling (37). Hypoxia, a condition frequently associated with glioma, upregulates CXCR4, urokinase plasminogen activator receptor and VEGF receptor 2 on NSCs, which enhances their migration towards gliomas (38). The tumor tropism of iPSCs is enhanced by stem cell factor (SCF), PDGF-BB, SDF- $1 \alpha$ and VEGF, and the receptors of those factors (c-Kit, intercellular adhesion molecule 1, CXCR4 and VEGFR-2) are upregulated in the iPSCs (30).

The interaction between MSCs and the extracellular matrix (ECM) is significant, particularly in highly migrating MSCs (39). As mentioned previously, multiple factors influence the tumor tropism of stem cells. Further studies are required to integrate these in vitro factors into a comprehensive mechanism underlying stem cell migration. Since the in vivo tumor microenvironment is markedly more complex, further in vivo cell-tracking studies are required for the development of improved clinical protocols using stem cells as therapeutic vehicles for the treatment of gliomas (40).

\section{Types of cell vector}

NSCs are mainly located in the subependymal zone of the lateral ventricles and the dentate gyrus of the hippocampus, and are capable of differentiating into neurons, astrocytes and oligodendrocytes (41). Since the first study regarding tumor-tropic migration of the immortalized murine NSC line C17.2 (13), numerous in vivo studies using NSCs to deliver anti-tumor substances to gliomas have been conducted (17,42-50). Although NSCs may be obtained, even from the adult human brain, it is not easy to quickly expand, modify and characterize these cells in preparation for implantation into GBM patients with a short life expectancy. Therefore, it is possible that immortalized NSC lines that are readily available may be used (https://clinicaltrials.gov/; identifier, NCT01172964). A well-characterized NSC line is able to be cultured and expanded in vitro to obtain high numbers of cells ready for transplantation within a short period, as long as the problems associated with immunogenicity and tumorigenicity are solved by, for example, steroid administration. In 2010, a clinical pilot trial using genetically engineered immortalized NSCs was initiated for patients with recurrent high-grade gliomas, where NSCs were applied at the time of surgery (https://clinicaltrials.gov/; identifier, NCT01172964).

MSCs are multipotent stem cells located in the bone marrow, adipose tissue, umbilical cord and placenta, which are able to differentiate into cells of mesenchymal lineage, including osteoblasts, adipocytes, chondrocytes and myocytes $(51,52)$. It is significantly easier to obtain MSCs, for example, via bone marrow aspiration, than NSCs. The relatively easy availability of these cells makes it possible to graft autologous MSCs (isolated from the patient), facilitating the avoidance of graft rejection. However, the expansion, modification and characterization of these MSCs delays the initiation of treatment, compared with that of implantation of readily available, well-characterized, existing cell lines. In addition, there are a variety of concerns regarding the use of MSCs for gene therapy in the treatment of tumors. MSCs may contribute to tumor growth via their immunosuppressive function (53), growth factor production (54) and contributions to pro-tumorigenic stroma (55), as well as through malignant transformation of the recruited MSCs, which may induce tumor growth $(53,56,57)$. The interaction between MSCs and tumor cells, and the potential risk of MSC transformation into malignant cells remain controversial (58-60). MSCs and NSCs have similar tumor tropism and infiltrative potential across the BBB (61). Intracranially implanted MSCs have demonstrated tropism for experimental gliomas, where 
MSCs were able to successfully deliver therapeutic substances, thereby contributing to the increased survival of glioma-bearing model animals $(14,15)$.

Hematopoietic progenitor cells are a readily available cell type, which exhibit marked glioma tropism $(62,63)$. Implantation of human skin-derived stem cells, which are able to migrate to experimental gliomas and inhibit tumor angiogenesis, may present an autologous stem cell therapy for the treatment of gliomas (64). Systemically injected endothelial progenitor cells have been demonstrated to be able to target experimental gliomas and assimilate into the tumor vasculature $(65,66)$. Endothelial progenitor cells have been genetically modified to produce oncolytic measles virus and tested as a potential anti-glioma therapy (67), or engineered to express cytotoxic anti-tumor genes (65). Embryonic stem cell-derived astrocytes have demonstrated intracranial migratory potential and therapeutic efficacy following implantation into subcutaneously established gliomas (68). In addition, NSCs derived from iPSCs have also been used as vectors in gene therapy for experimental glioma (69).

\section{Cytokine-based therapy}

Various types of cytokine have been delivered to gliomas, by NSC or MSC, and have demonstrated therapeutic efficacy $(14,43,70,71)$. Positive therapeutic effects of intratumoral injection of IL-4-producing NSCs on murine glioma growth have been identified (42). NSC-produced IL-4 exerted more powerful anti-tumor effects than that of virus-mediated transfer of IL-4 (42). The capabilities of genetically engineered NSCs and MSCs expressing therapeutic cytokines IL-2 (72), IL-7 (70), IL-12 (43), IL-18 (73) and IL-23 (71) to augment the immune response to the tumor were also evaluated. TNF-related apoptosis-inducing ligand (TRAIL) activates the pro-apoptotic death receptors 4 and 5, which trigger caspase-8-dependent apoptosis (74). TRAIL is able to selectively target tumor cells, whilst sparing the majority of non-malignant cells (75). The tumor-specific therapeutic effect of TRAIL-producing NSCs, MSCs and ESC-derived astrocytes have been shown in several studies of experimental gliomas (76-79). A study, which simulated the clinical scenario of GBM treatment, demonstrated that inoculation of stem cells encapsulated in a biodegradable, synthetic ECM in the resection cavity following surgical debulking of human GBM tumors in mice, effectively inhibited tumor regrowth (80).

\section{Enzyme/prodrug-based therapy ('suicide' gene therapy)}

Enzyme/prodrug systems, which are also known as 'suicide gene therapies,' have been the most widely used type of gene therapy for glioma treatment. Among these systems, the HSV-tk/GCV system has been the most extensively studied. The HSV-tk gene phosphorylates non-toxic GCV into a toxic GCV-monophosphate in the cells, which is then further phosphorylated by cellular enzymes to GCV-triphosphate. Incorporation of GCV-triphosphate into the DNA results in chain termination of the DNA (10). Activated GCV is toxic not only to the HSV-tk-producing cells, but also to the cells in their vicinity, a phenomenon known as the 'bystander effect'. Since GCV-triphosphate is a relatively large molecule, the bystander effect is hypothesized to be mediated by gap junctions between cells, through which the phosphorylated prodrug is able to be transported (81). In addition, connexin 43 expression is important for the bystander effect (82). Migratory stem cell vectors have been introduced to achieve improved intratumoral distribution of the prodrug-converting enzyme. In vivo preclinical studies confirming the feasibility of this approach for the treatment of glioma have been conducted using NSCs $(17,44,83)$ and MSCs $(81,84-90)$ as HSV-tk delivery vehicles. It has also been proven that the 'bystander effect' of HSV-tk/GCV suicide gene therapy does not damage normal brain tissues (91).

Cytosine deaminase (CD) is another well-investigated prodrug-activating enzyme, which converts 5-fluorocytosine (5-FC) to its toxic form, 5-fluorouracil (5-FU), thereby inducing cell death (92). 5-FU is able to diffuse across cell membranes without requiring direct cell-to-cell contact, and exerts a marked bystander effect (93). Since the first report regarding the use of CD-expressing NCSs for the treatment of intracranial rat gliomas (13), multiple in vivo preclinical studies have demonstrated the treatment efficacy of the use of NSCs $(18,93-95)$ and MSCs (96-98). As previously mentioned, a clinical pilot trial using immortalized NSCs engineered to produce CD, in combination with oral 5-FC administration, commenced in 2010. This pilot was for patients with recurrent high-grade gliomas, and aimed to examine whether intracerebral NSC implantation and systemic 5-FC administration was safe and feasible.

Rabbit carboxylesterase (CE) is able to convert, more efficiently than human CE (99), the prodrug CPT-11 into the cytotoxic drug 7-ethyl-10-hydroxycamptothecin, which functions as a potent inhibitor of topoisomerase I (100). Intratumoral injection of genetically modified MSCs expressing rabbit CE, in combination with systemic administration of CPT-11, modestly prolonged the survival of brainstem glioma-bearing rats (101). Cytochrome P450 2B6 (CYP2B6) catalyzes the transformation of cyclophosphamide (CPA) into the non-toxic metabolite, 4-hydroxy CPA (102). Co-cultures of CYP2B6-NSC with human CPA-treated U87 Mg glioma cells demonstrated significant bystander effect-mediated cytotoxic effects on tumor cells (102). A further in vivo study demonstrated that intracerebral inoculation of CYP2B6-NSCs, prior to intracerebral administration of CPA, effectively inhibited the growth of aggressive high-grade gliomas (46). Previous studies regarding these 'suicide gene therapies' are summarized in Table I.

\section{Oncolytic virus-based therapy}

Oncolytic virotherapy describes the process where viruses with the capacity to infect tumor cells are delivered to tumors. The viruses are able to replicate within and subsequently lyse the tumor cells. Following cell lysis, the viral particles are released and thus infect the neighboring tumor cells. However, the distribution of locally injected viruses throughout the tumor tissue and to invasive tumor cells is difficult. Furthermore, the viral particles may be attacked and neutralized by the host immune system prior to the exertion of any effects (103). To circumvent these obstacles, tumor-tropic migratory cells may be used to deliver viral particles to the distant parts of tumor and to protect against their attack by the immune system (23). Preclinical experiments using NSCs $(49,104,105)$ and MSCs (106-108) have demonstrated extended delivery of 
Table I. Summary of previous preclinical stem cell-based enzyme/prodrug therapies for brain tumors.

\begin{tabular}{|c|c|c|c|c|c|c|}
\hline Cell line (species) & Tumor type (species) & Experimental animal & Enzyme gene & Prodrug & Ref & Year \\
\hline NSC (rat) & C6 (rat) & SD rat & HSV-tk & GCV & (17) & 2005 \\
\hline NSC (mouse) C17.2 & CNS-1 (rat) & Nude mouse & $\mathrm{CD}$ & $5-\mathrm{FC}$ & (12) & 2000 \\
\hline NSC (rat) ST14A & C6 (rat) & SD rat & $\mathrm{CD}$ & $5-\mathrm{FC}$ & (94) & 2003 \\
\hline NSC (human) HB1.F3 & Daoy (human) & Nude mouse & $\mathrm{CD}$ & $5-\mathrm{FC}$ & (95) & 2007 \\
\hline NSC (human) HB1.F3 & Neuroblastoma (human) & SCID mouse & $\mathrm{rCE}$ & CPT-11 & $(100)$ & 2007 \\
\hline NSC (mouse) & GL261 (mouse) & C57B1/6 mouse & CYP2B6 & $\mathrm{CPA}$ & $(102)$ & 2008 \\
\hline NSC (mouse) & U87 (human) & Nude mouse & CYP2B6 & $\mathrm{CPA}$ & $(46)$ & 2010 \\
\hline MSC (rat) & 9L (rat) & Fischer rat & HSV-tk & GCV & (84) & 2007 \\
\hline MSC (rat) & 9L (rat) & SD rat & HSV-tk & GCV & $(85)$ & 2009 \\
\hline MSC (rat) & C6 (rat) & SD rat & HSV-tk & GCV & (86) & 2009 \\
\hline MSC (human) iv & 8-MG-BA (human) & Nude mouse & HSV-tk & GCV & (81) & 2010 \\
\hline MSC (human) iv & U87 (human) & Nude mouse & HSV-tk & GCV & (89) & 2010 \\
\hline MSC (rat) & 9L (rat) & Fischer rat & HSV-tk & GCV & (88) & 2010 \\
\hline MSC (human) & A172, T98G (human) & Nude mouse & HSV-tk & GCV & (90) & 2012 \\
\hline MSC (rat) & 9L (rat) & Nude mouse & $\mathrm{CD}$ & $5-\mathrm{FC}$ & (98) & 2012 \\
\hline MSC (human) & C6 (rat) & SD rat & CD:UPRT & $5-\mathrm{FC}$ & (97) & 2012 \\
\hline MSC (human) & F98 (rat) & Fischer rat & $\mathrm{rCE}$ & CPT-11 & $(101)$ & 2012 \\
\hline
\end{tabular}

NSC, neural stem cell; MSC, mesenchymal stem cell; SD, Sprague-Dawley; HSV-tk, herpes simplex virus-thymidine kinase; CD, cytosine deaminase; rCE, rabbit liver carboxylesterase; CYP2B6, cytochrome P450 2B6; UPRT, uracil phosphoribosyltransferase; GCV, ganciclovir; 5-FC, 5-fluorocytosine ; CPT-11, camptothecin-11; CPA, cyclophosphamide.

oncolytic viruses and prolonged survival of glioma-bearing animals treated with stem cell-mediated oncolytic virotherapy.

\section{Conclusion}

Neural, mesenchymal and other types of stem cell, engineered to express various therapeutic genes are attractive candidates for use in the treatment of malignant glioma patients. For the evaluation of such novel treatment strategies, cases of glioma which are recurrent following standard therapy, including radiotherapy with temozolomide-based chemotherapy, should be selected for the study cohort. Implanting genetically modified stem cells into any remaining tumor tissue following surgical resection, or stereotactically injecting stem cells into the unresectable tumor are two potential treatment modalities (17). These treatments may prolong the period of re-remission, without inducing the serious side effects associated with more extensive chemotherapeutic strategies (6). In addition, repeated treatment may be possible as a number of the treatment substances employed are essentially non-toxic to humans.

However, despite the abundance of basic findings that support the use of stem cell vectors in tumor therapy, there are also several issues regarding the translation of this strategy into a clinical setting. These issues include the choice of cell vector and therapeutic transgene, as well as the optimal route of administration (for example, intratumoral or intravenous administration). Teratogenicity of the stem cells, particularly that of MSCs, is one of the most significant concerns to be solved prior to the commencement of clinical studies, even when the targets of treatment are fatal diseases, for example
GBM. The interaction between MSCs and tumor cells and the potential risk of MSCs transforming into malignant cells remain controversial (58-60). Therefore, the use of readily available well-characterized MSCs, for example the C17.2 NSC line, is suggested. The use of stem cells transduced with suicide genes, for example the HSV-tk gene, to eliminate transplanted therapeutic stem cells may function as an additional 'safety valve'. As a result of the promising preclinical results regarding the use of stem cell-based therapy for glioblastomas, clinical studies should be conducted under careful clinical protocols, including sophisticated imaging techniques for evaluating the fate of the implanted stem cells (40).

\section{References}

1. Narita Y and Shibui S; Committee of Brain Tumor Registry of Japan Supported by the Japan Neurosurgical Society: Trends and outcomes in the treatment of gliomas based on data during 2001-2004 from the Brain Tumor Registry of Japan. Neurol Med Chir (Tokyo) 55 Suppl 1: 286-295, 2015.

2. Stupp R, Hegi M, Mason W, van den Bent MJ, Taphoorn MJ, Janzer RC, Ludwin SK, Allgeier A, Fisher B, Belanger K, et al: Effects of radiotherapy with concomitant and adjuvant temozolomide versus radiotherapy alone on survival in glioblastoma in a randomised phase III study: 5-year analysis of the EORTC-NCIC trial. Lancet Oncol 10: 459-466, 2009.

3. Stupp R, Mason WP, ven den Bent MJ, Weller M, Fisher B, Taphoorn MJ, Belanger K, Brandes AA, Marosi C, Bogdahn U, et al: Radiotherapy plus concomitant and adjuvant temozolomide for glioblastoma. NEngl J Med 352: 987-996, 2005.

4. Hochberg F and Pruitt A: Assumptions in the radiotherapy of glioblastoma. Neurology 30: 907-911, 1980.

5. Okamoto Y, Di Patre P, Burkhard C, et al: Population-based study on incidence, survival rates and genetic alterations of low-grade diffuse astrocytomas and oligodendrogliomas. Acta Neuropathol 108: 49-56, 2004. 
6. Wen $\mathrm{P}$ and Kesari S: Malignant gliomas in adults. N Engl J Med 359: 492-507, 2008

7. Bonavia R, Inda MM, Cavenee $\mathrm{WK}$ and Furnari FB: Heterogeneity maintenance in glioblastoma: A social network. Cancer Res 71: 4055-4060, 2011

8. Kesari S: Understanding glioblastoma tumor biology: The potential to improve current diagnosis and treatments. Semin Oncol 38 (Suppl 4): S2-S10, 2011.

9. Rich J and Bigner DD: Development of novel targeted therapies in the treatment of malignant glioma. Nat Rev Drug Discov 3 : 430-446, 2004

10. Rainov NG: A phase III clinical evaluation of herpes simplex virus type 1 thymidine kinase and ganciclovir gene therapy as an adjuvant to surgical resection and radiation in adults with previously untreated glioblastoma multiforme. Hum Gene Ther 11: 2389-2401, 2000

11. Lawler SE, Peruzzi PP and Chiocca EA: Genetic strategies for brain tumor therapy. Cancer Gene Ther 13: 225-233, 2006.

12. Pulkkanen KJ and Yla-Herttuala S: Gene therapy for malignant glioma: Current clinical status. Mol Ther 12: 585-598, 2005.

13. Aboody KS, Brown A, Rainov NG, Bower KA, Liu S, Yang W, Small JE, Herrlinger U, Ourednik V, Black PM, et al: Neural stem cells display extensive tropism for pathology in adult brain: Evidence from intracranial gliomas. Proc Natl Acad Sci USA 97: 12846-12851, 2000

14. Nakamizo A, Marini F, Amano T, Khan A, Studeny M, Gumin J, Chen J, Hentschel S, Vecil G, Dembinski J, et al: Human bone marrow-derived mesenchymal stem cells in the treatment of gliomas. Cancer Res 65: 3307-3318, 2005

15. Nakamura K, Ito Y, Kawano Y, Kurozumi K, Kobune M, Tsuda H, Bizen A, Honmou O, Niitsu Y and Hamada H: Antitumor effect of genetically engineered mesenchymal stem cells in a rat glioma model. Gene Ther 11: 1155-1164, 2004.

16. Bexell D, Gunnarsson S, Tormin A, Darabi A, Gisselsson D, Roybon L, Scheding S and Bengzon J: Bone marrow multipotent mesenchymal stroma cells act as pericyte-like migratory vehicles in experimental gliomas. Mol Ther 17: 183-190, 2009.

17. Li S, Tokuyama T, Yamamoto J, Koide M, Yokota N and Namba H: Bystander effect-mediated gene therapy of gliomas using genetically engineered neural stem cells. Cancer Gene Ther 12: 600-607, 2005.

18. Aboody KS, Najbauer J and Danks MK: Stem and progenitor cell-mediated tumor selective gene therapy. Gene Ther 15 : 739-752, 2008

19. Dvorak HF: Tumors: Wounds that do not heal. Similarities between tumor stroma generation and wound healing. N Engl J Med 315: 1650-1659, 1986.

20. Einstein $\mathrm{O}$ and Ben-Hur T: The changing face of neural stem cell therapy in neurologic diseases. Arch Neurol 65: 452-456, 2008.

21. English K and Wood K: Immunogenicity of embryonic stem cell-derived progenitors after transplantation. Curr Opin Organ Transplant 16: 90-95, 2011.

22. Jones BJ and McTaggart SJ: Immunosuppression by mesenchymal stromal cells: From culture to clinic. Exp Hematol 36: 733-741, 2008

23. Power AT and Bell JC: Cell-based delivery of oncolytic viruses: A new strategic alliance for a biological strike against cancer. Mol Ther 15: 660-665, 2007.

24. Engelhorn T, Savaskan NE, Schwarz MA, Kreutzer J, Meyer EP Hahnen E, Ganslandt O, Dörfler A, Nimsky C, Buchfelder M and Eyüpoglu IY: Cellular characterization of the peritumoral edema zone in malignant brain tumors. Cancer Sci 100 1856-1862, 2009.

25. Spaeth E, Klopp A, Dembinski J, Andreeff M and Marini F: Inflammation and tumor microenvironments: Defining the migratory itinerary of mesenchymal stem cells. Gene Ther 15 : $730-738,2008$

26. Kim DS, Kim JH, Lee JK, Choi SJ, Kim JS, Jeun SS, Oh W, Yang YS and Chang JW: Overexpression of CXC chemokine receptors is required for the superior glioma-tracking property of umbilical cord blood-derived mesenchymal stem cells. Stem Cells Dev 18: 511-519, 2009.

27. Dwyer RM, Potter-Beirne SM, Harrington KA, et al: Monocyte chemotactic protein-1 secreted by primary breast tumors stimulates migration of mesenchymal stem cells. Clin Cancer Res 13: 5020-5027, 2007.

28. Menon LG, Picinich S, Koneru R, et al: Differential gene expression associated with migration of mesenchymal stem cells to conditioned medium from tumor cells or bone marrow cells. Stem Cells 25: 520-528, 2007.
29. Egea V, von Baumgarten L, Schichor C, et al: TNF- $\alpha$ respecifies human mesenchymal stem cells to a neural fate and promotes migration toward experimental glioma. Cell Death Differ 18: 853-863, 2011.

30. Koizumi S, Gu C, Amano S, Yamamoto S, Ihara H, Tokuyama T and Namba H: Migration of mouse-induced pluripotent stem cells to glioma-conditioned medium is mediated by tumor-associated specific growth factors. Oncol Lett 2: 283-288, 2011.

31. Yamazoe T, Koizumi S, Yamasaki T, Amano S, Tokuyama T and Namba H: Potent tumor tropism of induced pluripotent stem cells and induced pluripotent stem cell-derived neural stem cells in the mouse intracerebral glioma model. Int J Oncol 46: 147-152, 2015.

32. Magge SN, Malik SZ, Royo NC, Chen HI, Yu L, Snyder EY, O'Rourke DM and Watson DJ: Role of monocyte chemoattractant protein-1 (MCP-1/CCL2) in migration of neural progenitor cells toward glial tumors. J Neurosci Res 87: 1547-1555, 2009.

33. Kim SM, Oh JH, Park SA, Ryu CH, Lim JY, Kim DS, Chang JW, Oh W and Jeun SS: Irradiation enhances the tumor tropism and therapeutic potential of tumor necrosis factor-related apoptosis-inducing ligand-secreting human umbilical cord blood-derived mesenchymal stem cells in glioma therapy. Stem Cells 28: 2217-2228, 2010.

34. Klopp AH, Spaeth EL, Dembinski JL, Woodward WA, Munshi A, Meyn RE, Cox JD, Andreeff M and Marini FC: Tumor irradiation increases the recruitment of circulating mesenchymal stem cells into the tumor microenvironment. Cancer Res 67: $11687-11695,2007$

35. Birnbaum T, Roider J, Schankin CJ, Padovan CS, Schichor C, Goldbrunner R and Straube A: Malignant gliomas actively recruit bone marrow stromal cells by secreting angiogenic cytokines. J Neurooncol 83: 241-247, 2007.

36. Schichor C, Birnbaum T, Etminan N, Schnell O, Grau S, Miebach S, Aboody K, Padovan C, Straube A, Tonn JC and Goldbrunner R: Vascular endothelial growth factor A contributes to glioma-induced migration of human marrow stromal cells (hMSC). Exp Neurol 199: 301-310, 2006.

37. Schmidt NO, Przylecki W, Yang W, Ziu M, Teng Y, Kim SU, Black PM, Aboody KS and Carroll RS: Brain tumor tropism of transplanted human neural stem cells is induced by vascular endothelial growth factor. Neoplasia 7: 623-629, 2005

38. Zhao D, Najbauer J, Garcia E, Metz MZ, Gutova M, Glackin CA, Kim SU and Aboody KS: Neural stem cell tropism to glioma: Critical role of tumor hypoxia. Mol Cancer Res 6: 1819-1829, 2008

39. Ho IA, Chan KY, Ng WH, Guo CM, Hui KM, Cheang P and Lam PY: Matrix metalloproteinase 1 is necessary for the migration of human bone marrow-derived mesenchymal stem cells toward human glioma. Stem Cells 27: 1366-1375, 2009.

40. Martinez-Quintanilla J, Bhere D, Heidari P, He D, Mahmood U and Shah K: Therapeutic efficacy and fate of bimodal engineered stem cells in malignant brain tumors. Stem Cells 31: 1706-1714, 2013.

41. Gage FH: Mammalian neural stem cells. Science 287 1433-1438, 2000

42. Benedetti S, Pirola B, Pollo B, Magrassi L, Bruzzone MG, Rigamonti D, Galli R, Selleri S, Di Meco F, De Fraja C, et al: Gene therapy of experimental brain tumors using neural progenitor cells. Nat Med 6: 447-450, 2000

43. Ehtesham M, Kabos P, Kabosova A, Neuman T, Black KL and Yu JS: The use of interleukin 12-secreting neural stem cells for the treatment of intracranial glioma. Cancer Res 62: 5657-5663, 2002.

44. Kim SK, Cargioli TG, Machluf M, Yang W, Sun Y, Al-Hashem R, Kim SU, Black PM and Carroll RS: PEX-producing human neural stem cells inhibit tumor growth in a mouse glioma model. Clin Cancer Res 11: 5965-5970, 2005

45. Li S, Gao Y, Tokuyama T, Yamamoto J, Yokota N, Yamamoto S, Terakawa S, Kitagawa M and Namba H: Genetically engineered neural stem cells migrate and suppress glioma cell growth at distant intracranial sites. Cancer Lett 251: 220-227, 2007.

46. Mercapide J, Rappa G, Anzanello F, King J, Fodstad O and Lorico A: Primary gene-engineered neural stem/progenitor cells demonstrate tumor-selective migration and antitumor effects in glioma. Int J Cancer 126: 1206-1215, 2010.

47. Shah K, Hingtgen S, Kasmieh R, Figueiredo JL, Garcia-Garcia E, Martinez-Serrano A, Breakefield X and Weissleder R: Bimodal viral vectors and in vivo imaging reveal the fate of human neural stem cells in experimental glioma model. J Neurosci 28 : 4406-4413, 2008.

48. Thu MS, Najbauer J, Kendall SE, Harutyunyan I, Sangalang N, Gutova M, Metz MZ, Garcia E, Frank RT, Kim SU, et al: Iron labeling and pre-clinical MRI visualization of therapeutic human neural stem cells in a murine glioma model. PLoS One 4: e7218, 2009. 
49. Tyler MA, Ulasov IV, Sonabend AM, Nandi S, Han Y, Marler S, Roth J and Lesniak MS: Neural stem cells target intracranial glioma to deliver an oncolytic adenovirus in vivo. Gene Ther 16 262-278, 2009

50. Staflin K, Honeth G, Kalliomäki S, Kjellman C, Edvardsen K and Lindvall M: Neural progenitor cell lines inhibit rat tumor growth in vivo. Cancer Res 64: 5347-5354, 2004

51. Picinich SC, Mishra PJ, Mishra PJ, Glod J and Banerjee D: The therapeutic potential of mesenchymal stem cells. Cell- \& tissue-based therapy. Expert Opin Biol Ther 7: 965-973, 2007.

52. Caplan Al: Why are MSCs therapeutic? New data: New insight J Pathol 217: 318-324, 2009.

53. Djouad F, Plence P, Bony C, Tropel P, Apparailly F, Sany J, Noël D and Jorgensen C: Immunosuppressive effect of mesenchymal stem cells favors tumor growth in allogeneic animals. Blood 102: 3837-3844, 2003.

54. Beckermann B, Kallifatidis G, Groth A, et al: VEGF expression by mesenchymal stem cells contributes to angiogenesis in pancreatic carcinoma. Br J Cancer 99: 622-631, 2008.

55. Coffelt SB, Marini FC, Watson K, Zwezdaryk KJ, Dembinski JL, LaMarca HL, Tomchuck SL, Honer zu Bentrup K, Danka ES, Henkle SL and Scandurro AB: The pro-inflammatory peptide LL-37 promotes ovarian tumor progression through recruitment of multipotent mesenchymal stromal cells. Proc Natl Acad Sci USA 106: 3806-3811, 2009

56. Houghton J, Stoicov C, Nomura S, et al: Gastric cancer originating from bone marrow-derived cells. Science 306: 1568-1571, 2004.

57. Spaeth EL, Dembinski JL, Sasser AK, Watson K, Klopp A, Hall B, Andreeff M and Marini F: Mesenchymal stem cell transition to tumor-associated fibroblasts contributes to fibrovascular network expansion and tumor progression. PLoS One 4 : e 4992, 2009

58. Klopp AH, Gupta A, Spaeth E, Andreeff M and Marini F III: Concise review: Dissecting a discrepancy in the literature: Do mesenchymal stem cells support or suppress tumor growth? Stem Cells 29: 11-19, 2011.

59. Prockop DJ, Brenner M, Fibbe WE, Horwitz E, Le Blanc K Phinney DG, Simmons PJ, Sensebe L and Keating A: Defining the risks of mesenchymal stromal cell therapy. Cytotherapy 12 : $576-578,2010$

60. Rubio D, Garcia-Castro J, Martín MC, de la Fuente R, Cigudosa JC, Lloyd AC and Bernad A: Spontaneous human adult stem cell transformation. Cancer Res 65: 3035-3039, 2005.

61. Ahmed AU, Tyler MA, Thaci B, Alexiades NG, Han Y, Ulasov IV and Lesniak MS: A comparative study of neural and mesenchymal stem cell-based carriers for oncolytic adenovirus in a model of malignant glioma. Mol Pharm 8: 1559-1572, 2011.

62. Tabatabai G, Bähr O, Möhle R, Eyüpoglu IY, Boehmler AM, Wischhusen J, Rieger J, Blümcke I, Weller M and Wick W: Lessons from the bone marrow: How malignant glioma cells attract adult haematopoietic progenitor cells. Brain 128: 2200-2211, 2005.

63. Tabatabai G, Wick W and Weller M: Stem cell-mediated gene therapies for malignant gliomas: A promising targeted therapeutic approach? Discov Med 11: 529-536, 2011.

64. Pisati F, Belicchi M, Acerbi F, Marchesi C, Giussani C, Gavina M, Javerzat S, Hagedorn M, Carrabba G, Lucini V, et al: Effect of human skin-derived stem cells on vessel architecture, tumor growth and tumor invasion in brain tumor animal models. Cancer Res 67: 3054-3063, 2007.

65. Ferrari N, Glod J, Lee J, Kobiler D and Fine HA: Bone marrow-derived, endothelial progenitor-like cells as angiogenesis-selective gene-targeting vectors. Gene Ther 10 : 647-656, 2003

66. Moore XL, Lu J, Sun L, Zhu CJ, Tan P and Wong MC: Endothelial progenitor cells' 'homing' specificity to brain tumors. Gene Ther 11: 811-818, 2004

67. Wei J, Wahl J, Nakamura T, et al: Targeted release of oncolytic measles virus by blood outgrowth endothelial cells in situ inhibits orthotopic gliomas. Gene Ther 14: 1573-1586, 2007.

68. Uzzaman M, Keller G and Germano IM: In vivo gene delivery by embryonic-stem-cell-derived astrocytes for malignant gliomas. Neuro Oncol 11: 102-108, 2009.

69. Lee EX, Lam DH, Wu C, Yang J, Tham CK, Ng WH and Wang S: Glioma gene therapy using induced pluripotent stem cell derived neural stem cells. Mol Pharm 8: 1515-1524, 2011.

70. Gunnarsson S, Bexell D, Svensson A, Siesjö P, Darabi A and Bengzon J: Intratumoral IL-7 delivery by mesenchymal stromal cells potentiates IFNgamma-transduced tumor cell immunotherapy of experimental glioma. J Neuroimmunol 218: $140-144,2010$
71. Yuan X, Hu J, Belladonna ML, Black KL and Yu JS Interleukin-23-expressing bone marrow-derived neural stem-like cells exhibit antitumor activity against intracranial glioma. Cancer Res 66: 2630-2638, 2006

72. Stagg J, Lejeune L, Paquin A and Galipeau J: Marrow stromal cells for interleukin-2 delivery in cancer immunotherapy. Hum Gene Ther 15: 597-608, 2004.

73. Xu G, Jiang XD, Xu Y, , Zhang J, Huang FH, Chen ZZ, Zhou DX, Shang JH, Zou YX, Cai YQ, et al: Adenoviral-mediated interleukin-18 expression in mesenchymal stem cells effectively suppresses the growth of glioma in rats. Cell Biol Int 33: 466-474, 2009.

74. Kelley SK and Ashkenazi A: Targeting death receptors in cancer with Apo2 L/TRAIL. Curr Opin Pharmacol 4: 333-339, 2004.

75. Almasan A and Ashkenazi A: Apo2 L/TRAIL: Apoptosis signaling, biology and potential for cancer therapy. Cytokine Growth Factor Rev 14: 337-348, 2003.

76. Sasportas LS, Kasmieh R, Wakimoto H, Hingtgen S, van de Water JA, Mohapatra G, Figueiredo JL, Martuza RL, Weissleder R and Shah K: Assessment of therapeutic efficacy and fate of engineered human mesenchymal stem cells for cancer therapy. Proc Natl Acad Sci USA 106: 4822-4827, 2009.

77. Kim SM, Lim JY, Park SI, Jeong CH, Oh JH, Jeong M, Oh W, Park SH, Sung YC and Jeun SS: Gene therapy using TRAIL-secreting human umbilical cord blood-derived mesenchymal stem cells against intracranial glioma. Cancer Res 68: 9614-9623, 2008.

78. Menon LG, Kelly K, Yang HW, Kim SK, Black PM and Carroll RS: Human bone marrow-derived mesenchymal stromal cells expressing S-TRAIL as a cellular delivery vehicle for human glioma therapy. Stem Cells 27: 2320-2330, 2009.

79. Choi SA, Hwang SK, Wang KC, Cho BK, Phi JH, Lee JY, Jung HW, Lee DH and Kim SK: Therapeutic efficacy and safety of TRAIL-producing human adipose tissue-derived mesenchymal stem cells against experimental brainstem glioma. Neuro Oncol 13: 61-69, 2011.

80. Kauer TM, Figueiredo JL, Hingtgen S and Shah K: Encapsulated therapeutic stem cells implanted in the tumor resection cavity induce cell death in gliomas. Nat Neurosci 15: 197-204, 2011.

81. Matuskova M, Hlubinova K, Pastorakova A, Hunakova L, Altanerova V, Altaner C and Kucerova L: HSV-tk expressing mesenchymal stem cells exert bystander effect on human glioblastoma cells. Cancer Lett 290: 58-67, 2010.

82. Namba H, Iwadate Y, Kawamura K, Sakiyama S and Tagawa M: Efficacy of the bystander effect in the herpes simplex virus thymidine kinase-mediated gene therapy is influenced by the expression of connexin 43 in the target cells. Cancer Gene Ther 8: 414-420, 2001

83. Uhl M, Weiler M, Wick W, Jacobs AH, Weller $M$ and Herrlinger U: Migratory neural stem cells for improved thymidine kinase-based gene therapy of malignant gliomas. Biochem Biophys Res Commun 328: 125-129, 2005.

84. Miletic H, Fischer Y, Litwak S, Giroglou T, Waerzeggers Y, Winkeler A, Li H, Himmelreich U, Lange C, Stenzel W, et al: Bystander killing of malignant glioma by bone marrow-derived tumor-infiltrating progenitor cells expressing a suicide gene. Mol Ther 15: 1373-1381, 2007.

85. Uchibori R, Okada T, Ito T, Urabe M, Mizukami H, Kume A and Ozawa K: Retroviral vector-producing mesenchymal stem cells for targeted suicide cancer gene therapy. J Gene Med 11: 373-381, 2009.

86. Amano S, Li S, Gu C, Gao Y, Koizumi S, Yamamoto S, Terakawa S and Namba H: Use of genetically engineered bone marrow-derived mesenchymal stem cells for glioma gene therapy. Int J Oncol 35: 1265-1270, 2009.

87. Song C, Xiang J, Tang J, Hirst DG, Zhou J, Chan KM and Li G: Thymidine kinase gene modified bone marrow mesenchymal stem cells as vehicles for antitumor therapy. Hum Gene Ther 22: 439-449, 2011

88. Mori K, Iwata J, Miyazaki M, Osada H, Tange Y, Yamamoto T, Aiko Y, Tamura M and Shiroishi T: Bystander killing effect of tymidine kinase gene-transduced adult bone marrow stromal cells with ganciclovir on malignant glioma cells. Neurol Med Chir (Tokyo) 50: 545-553, 2010.

89. Bak XY, Yang J and Wang S: Baculovirus-transduced bone marrow mesenchymal stem cells for systemic cancer therapy. Cancer Gene Ther 17: 721-729, 2010.

90. Li S, Gu C, Gao Y, Amano S, Koizumi S, Tokuyama T and Namba H: Bystander effect in glioma suicide gene therapy using bone marrow stromal cells. Stem Cell Res 9: 270-276, 2012. 
91. Amano S, Gu C, Koizumi S, Tokuyama T and Namba $\mathrm{H}$ : Tumoricidal bystander effect in the suicide gene therapy using mesenchymal stem cells does not injure normal brain tissues. Cancer Lett 306: 99-105, 2011.

92. Fischer U, Steffens S, Frank S, Rainov NG, Schulze-Osthoff K and Kramm CM: Mechanisms of thymidine kinase/ganciclovir and cytosine deaminase/5-fluorocytosine suicide gene therapy-induced cell death in glioma cells. Oncogene 24: 1231-1243, 2005.

93. Ichikawa T, Tamiya T, Adachi Y, Ono Y, Matsumoto K, Furuta T, Yoshida Y, Hamada $\mathrm{H}$ and Ohmoto T: In vivo efficacy and toxicity of 5-fluorocytosine/cytosine deaminase gene therapy for malignant gliomas mediated by adenovirus. Cancer Gene Ther 7: 74-82, 2000.

94. Barresi V, Belluardo N, Sipione S, Mudò G, Cattaneo E and Condorelli DF: Transplantation of prodrug-converting neural progenitor cells for brain tumor therapy. Cancer Gene Ther 10: 396-402, 2003.

95. Shimato S, Natsume A, Takeuchi H, Wakabayashi T, Fujii M, Ito M, Ito S, Park IH, Bang JH, Kim SU and Yoshida J: Human neural stem cells target and deliver therapeutic gene to experimental leptomeningeal medulloblastoma. Gene Ther 14: 1132-1142, 2007.

96. Kucerova L, Altanerova V, Matuskova M, Tyciakova S and Altaner C: Adipose tissue-derived human mesenchymal stem cells mediated prodrug cancer gene therapy. Cancer Res 67 6304-6313, 2007

97. Altanerova V, Cihova M, Babic M, Rychly B, Ondicova K, Mravec B and Altaner C: Human adipose tissue-derived mesenchymal stem cells expressing yeast cytosinedeaminase::uracil phosphoribosyltransferase inhibit intracerebral rat glioblastoma. Int J Cancer 130: 2455-2463, 2012.

98. Kosaka H, Ichikawa T, Kurozumi K, Kambara H, Inoue S, Maruo T, Nakamura K, Hamada $\mathrm{H}$ and Date I: Therapeutic effect of suicide gene-transferred mesenchymal stem cells in a rat model of glioma. Cancer Gene Ther 19: 572-578, 2012.

99. Wierdl M, Morton CL, Weeks JK, Danks MK, Harris LC and Potter PM: Sensitization of human tumor cells to CPT-11 via adenoviral-mediated delivery of a rabbit liver carboxylesterase. Cancer Res 61: 5078-5082, 2001.
100. Danks MK, Yoon KJ, Bush RA, Remack JS, Wierdl M, Tsurkan L, Kim SU, Garcia E, Metz MZ, Najbauer J, et al: Tumor-targeted enzyme/prodrug therapy mediates long-term disease-free survival of mice bearing disseminated neuroblastoma. Cancer Res 67: 22-25, 2007.

101. Choi SA, Lee JY, Wang KC, Phi JH, Song SH, Song J and Kim SK: Human adipose tissue-derived mesenchymal stem cells: Characteristics and therapeutic potential as cellular vehicles for prodrug gene therapy against brainstem gliomas. Eur J Cancer 48: 129-137, 2012.

102. Lorico A, Mercapide J, Solodushko V, Alexeyev M, Fodstad O and Rappa G: Primary neural stem/progenitor cells expressing endostatin or cytochrome P450 for gene therapy of glioblastoma. Cancer Gene Ther 15: 605-615, 2008.

103. Yamamoto M and Curiel DT: Current issues and future directions of oncolytic adenoviruses. Mol Ther 18: 243-250, 2010.

104. Herrlinger U, Woiciechowski C, Sena-Esteves M, Aboody KS, Jacobs AH, Rainov NG, Snyder EY and Breakefield XO: Neural precursor cells for delivery of replication-conditional HSV-1 vectors to intracerebral gliomas. Mol Ther 1: 347-357, 2000.

105. Ahmed AU, Thaci B, Alexiades NG, Han Y, Qian S, Liu F, Balyasnikova IV, Ulasov IY, Aboody KS and Lesniak MS: Neural stem cell-based cell carriers enhance therapeutic efficacy of an oncolytic adenovirus in an orthotopic mouse model of human glioblastoma. Mol Ther 19: 1714-1726, 2011.

106. Sonabend AM, Ulasov IV, Tyler MA, Rivera AA, Mathis JM and Lesniak MS: Mesenchymal stem cells effectively deliver an oncolytic adenovirus to intracranial glioma. Stem Cells 26: 831-841, 2008

107. Yong RL, Shinojima N, Fueyo J, Gumin J, Vecil GG, Marini FC, Bogler O, Andreeff Mand Lang FF: Human bone marrow-derived mesenchymal stem cells for intravascular delivery of oncolytic adenovirus Delta24-RGD to human gliomas. Cancer Res 69: 8932-8940, 2009

108. Josiah DT, Zhu D, Dreher F, Olson J, McFadden G and Caldas H: Adipose-derived stem cells as therapeutic delivery vehicles of an oncolytic virus for glioblastoma. Mol Ther 18: 377-385, 2010. 